\title{
From suffering to resignation: Grounded Theory approach to maternal experience with newborn in phototherapy
}

Tayomara Ferreira Nascimento 1 Marla Andréia Garcia de Avila 2

Silvia Cristina Mangini Bocchi 3

${ }^{1}$ Gerência de Enfermagem. Hospital das Clínicas de Botucatu. Botucatu, SP, Brasil.

2,3 Departamento de Enfermagem. Faculdade de Medicina. Campus de Botucatu. Universidade Estadual Paulista Júlio de Mesquita Filho. Av. Prof. Mário Rubens Guimarães Montenegro, s.n. Botucatu, SP, Brasil. CEP: 18.618-970. E-mail: sbocchi@fmb.unesp.br

\begin{abstract}
Objectives:understanding the experience of puerperal womenwith newborn in phototherapy treatment in rooming-in care.

Methods:qualitative research analyzed according to the Grounded Theory and the results discussed in the light of Symbolic Interactionism. The interviews were audiotaped and transcribed in full. The theoretical saturation was based on the analysis of the 15th interview with puerperal women, undergoing the experience in the maternity of the Public Hospital of São Paulo State.

Results:from the analysis emerged four categories (sub processes): getting disappointed with the bad news; feeling recluse, separated from her baby, accountable and with not enough support for care; resigning to the protective role of mother of a baby in suffering and at risk; seeking strategies to deal with the situation. From the realignment of these categories (sub processes) emerged the core category (process): from suffering to resignation in order to deal with the maternal experience with $N B$ in phototherapy.

Conclusions:the symbolic intervening component, mother's protective role, prompted her to attempt to cope with the challenging experience by feeling compelled to exercise the function of caretaker. The same way that the rooming-in care team emerged in the experience of the mother, using the same symbol, to hold her accountable for constant vigilance in maintaining the integrity of baby's vision.

Key words Jaundice neonatal, Phototherapy, Rooming-in care, Maternal and child health, Qualitative research
\end{abstract}




\section{Introduction}

Neonatal jaundice affects $60 \%$ to $80 \%$ of newborns ${ }^{1-}$ 3 and phototherapy, as the only treatment used since 19584,5 in many countries, still lacks the use of technologies that preserve the skin-to-skin contact of the mother-child binomial.

In this context, the baby remains as long as possible, naked in a crib, only with genital and ocular protection, under a focus of continuous light. 1 Thus, the bilirubin in the irradiated subcutaneous tissue can be reduced and transformed into a watersoluble molecule, to be rapidly excreted by the biliary and urinary system. .6 With such treatment, the newborn (NB) is protected from the bilirubin neurotoxicity, from subtle manifestations to lack of coordination due to extrapyramidal dysfunction, including auditory neuropathy and sensor neural hearing loss. 7,8

There are different devices available for treatment of neonatal jaundice, from those employing halogen lamps, fiber optic and Light Emitting Diode (LED), or even sunlight (heliotherapy), 2 however, without international consensus on the best type of the lamp to be used. 5

The BiliBlanket, technology developed in 1990, is a high emission phototherapy system, by optical fiber blanket, which may be positioned under oron the body of the newborn, enabling it to be breastfed during the procedure without occluding their eyes. 9 It is imported technology and, therefore, little available in Brazilian health institutions.

Despite the benefits of phototherapy, the separation of the NB-mother binomial and the deficit of support to both may result in physical and psychic overloads, mainly for the mother.

The literature about the object of study (maternal experience with her NB in phototherapy) corroborates to a challenging experience, both in the physical and psychological aspects. ${ }^{8}$ However, there are few recent studies, exploring maternal experience and the role of nurses in care of the binomial. 10

Considering the epidemiological relevance of jaundice in NB; the overloads which mothers are submitted to; the possibility of non-adherence to treatment by the mother and the impairment of the child's health, as well as lack of research conducted according to the method proposed by this research, the need to explore the research problem initially proposed is sustained. Therefore, this study aims to: understanding the maternal experience with NB in phototherapy treatment in rooming-in care.

\section{Methods}

It is a qualitative research on the comprehensive approach, using methodological frameworks Grounded Theory ${ }^{11}$ and Symbolic Interactionism 12 as theoretical background.

The study was conducted in the Public Maternity Hospital from State of São Paulo, Brazil, with population coverage of 1.5 million users from 68 municipalities of a Regional Health Department (DRS). It has 40 beds exclusively destined to rooming-in care, performing in 2015 a monthly average of 59 caesarean deliveries and 110 vaginal deliveries.

At this time, the Institution followed the current basic standards, proposed by the Brazilian Ministry of Health, for implementationof "Rooming-in Care" system, with a multiprofessional team consisting of nursing (one nurse for 30 mother-child binomials and one auxiliary or nursing technician for every eight binomials); physicians (an obstetrician for 20 mothers and a pediatrician for 20 children); other professionals (Social Worker, Psychologist and Nutritionist). 13

The data collection was done by means of electronic medical record (sociodemographic, obstetrical and neonatal), and non-directive interview, held in a reserved room attached to the rooming-in care, having as a guiding question: Tell me how has been your experience with your baby's phototherapeutic treatment?

The interviews were audio recorded and conducted from August to September 2015, by one of the researchers with training in the collection of data technique, after the mothers of $\mathrm{NB}$ in phototherapy have accepted the invitation. There were two refusals, one due to weariness and physical exhaustion and another because of embarrassment at the interview recording.

In this study, we used intentional sampling and theoretical saturation, ${ }^{11}$ which was obtained with the analysis of the $15^{\text {th }}$ interview with mothers of NB in phototherapy, when data began to repeat and new events ceased to emerge, categories and subcategories proved to be sufficiently developed to form the theoretical model. In addition, the model was presented and validated by the participating mothers, who referred to represent their experiences, according to one of the ways of validating the model, recommended by Strauss and Corbin. ${ }^{11}$

It is emphasized as a criterion of mothers' inclusion, besides their interest in participating in the study, the fact that it was the second day of treatment, or from this, and that the baby couldn't 
have been hospitalized in the Intensive Care Unit or Intermediate Care Unit at any time of the experience for another diagnosis or treatments, that is, the ones whose hospitalization was only due to the need for phototherapy.

After transcribing the interviews in full and suppressing any information that could identify the mothers, an analysis was carried out according to the Grounded Theory steps ${ }^{11}$ :

-Microanalysis: detailed analysis line by line, necessary to generate initial categories (with their properties and dimensions), suggesting relationships between them and a combination of open and axial coding;

-Open coding: an analytical process wherewith concepts and their properties are identified and dimensions are discovered in the data. It allows conceptualizing the process of grouping similar items according to defined properties and giving the items a name that means this common link. In the conceptualization, large amounts of data are reduced. A concept is an abstract representation of an event, object, or action/interaction that a researcher identifies as meaningful in the data. Categories are concepts derived from data that represent phenomena. The concepts begin to be constituted when the analyst begins the process of grouping them or classifying them in more abstract terms, in categories;

-Axial coding: it is the process of relating categories to their subcategories, according to their properties and dimensions, systematically. This stage of analysis is important for the construction of theory;

-Selective coding: process of integration and improvement of theory. In the integration, the categories are organized around a central concept, through several techniques: to describe the history, using diagrams, classification and revision notes.

The maternal experience with NB in rooming-in care based phototherapy was analyzed in the light of Symbolic Interactionism. Four important aspects distinguish this theoretical framework from others in psychology: "1 - Symbolic Interactionism creates a more active image of the human being and rejects the image of a passive and determined organism. 2 the human being is understood as someone acting in the present, who is influenced not only by what happened in the past, but also by what is happening now. 3 -interaction is not only what is happening among people, but also what is taking place within the individuals. This definition may be influenced by those whom we interact with. It is also the result of our own definition, our interpretation of the situation. 4 - Symbolic Interactionism describes human beings as more active in their world than in other perspectives. 12

The concepts of Symbolic Interactionism are: symbol, self, mind, putting yourself in the other's shoes, human action and social interaction. 12

The interviews were carried out after approval of the research project by the Research Ethics Committee (CAAE 43060915.1.0000.5411; Advice number: 1.011.716) and obtaining the free and informed consent form of each puerperal woman with NB in phototherapy.

\section{Results}

\section{Characterization of the mother-NB binominal}

The 15 postpartum women who participated in the study were between 15 and 37 years old, with education from elementary school to high school, and family wage of one (252 USD) to four Brazilian minimum wages.Eight were primigravidae and seven were between the third and fifth pregnancies, and five reported previous experience with NB in phototherapy. In the process of analysis, it was unnecessary the formation of sample with mothers groups with or without previous experience, since they did not differentiate during the analyses.

The NB were born within 34 to 41 weeks of gestation, they were between the second and seventh day of life, in rooming-in careand exclusive breastfeeding.

\section{Theoretical model abstracted from experience}

From the analysis of the data, according to the steps of the Grounded Theory, the understanding of maternal experience with NB care in phototherapy was approached.

The categories identified and the established theoretical relations allowed the development of an analytical and explanatory process of actions and interactions that make up the process of caring for the NB by mother in the puerperium, involving the multi-professional team in this context, composed of four sub processes: (A) getting disappointed with the bad news; (B) feeling recluse, separated from her baby, accountable and with not enough support for care; (C) resigning to the protective role of baby's mother in suffering and risk; (D) seeking strategies to deal with the situation (Figure 1).

Getting disappointed with the bad news (A) is the first sub process from experience; it is due to the 
Central category (theoretical model) - From suffering to resignation to deal with the maternal experience with NB in phototherapy. Public Hospital from State of São Paulo, Brazil, 2015.

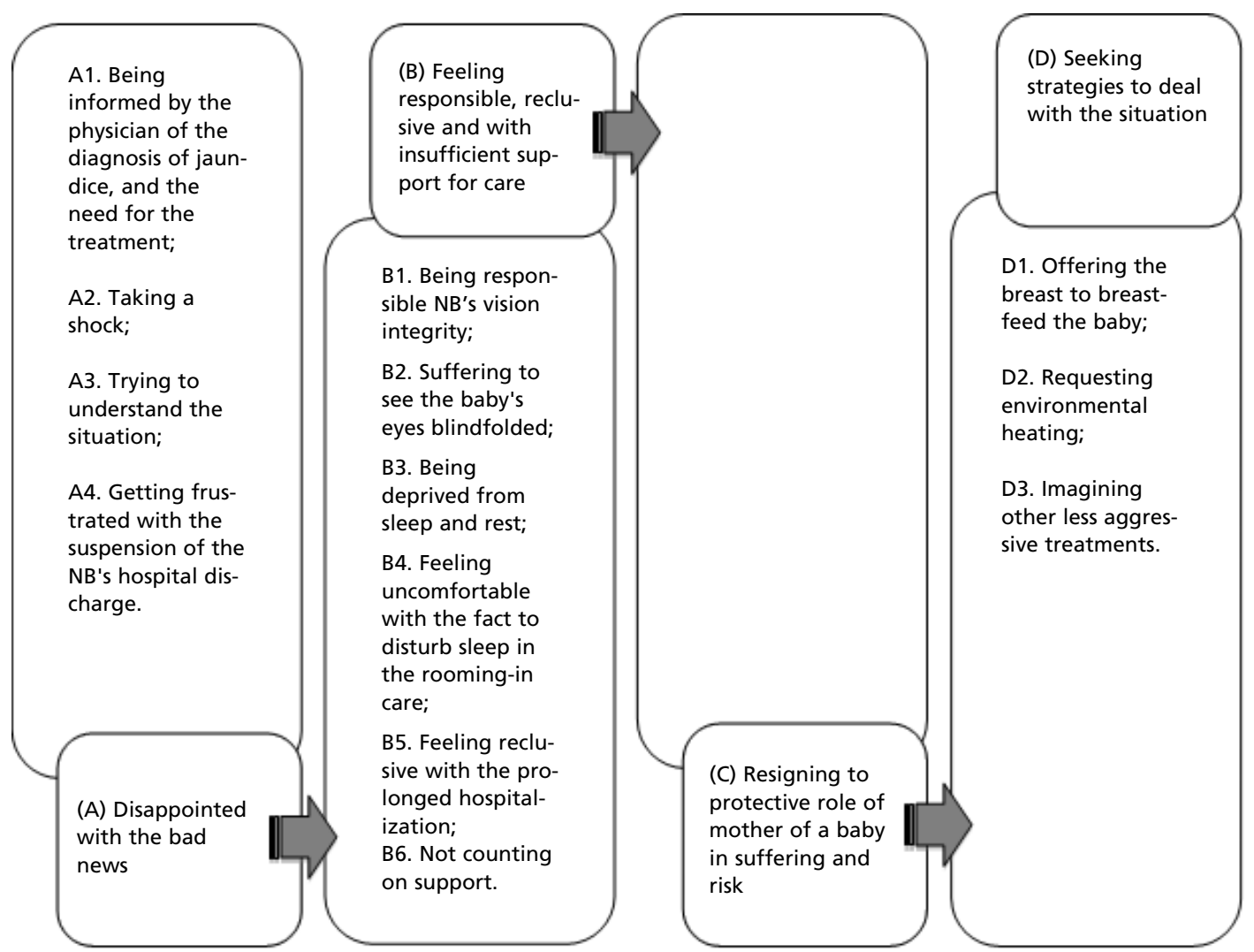

feeling of sadness, dissatisfaction and consequently frustration of the mother, facing the suspension of the expected hospital discharge at 48 hours of life of the NB.This sub process consists of the next four steps that follow, and begins when the mother in puerperal state, being informed by the physician of the diagnosis of jaundice, and the need for the treatment (A1).

Surprised at the suspension of the baby's discharge and, consequently, suddenly interrupted her expectations of returning home, the mother describes herself as if she had been shocked (A2). Shaken by the news that the baby needs to stay hospitalized, even guided by physicians, she remains discontented and crying most of the time, as Mother 5 reported:

[...] I was frightened because nobody told me that my baby would look like this. I was expecting to be discharged with my baby, but the nurse arrived and said, "You're OK, but your baby has to stay in the light bath." I asked, "But, why?" "Why?" [...].

After the impact of the news, the mother undertakes a movement trying to understand the situation (A3). A maternal reaction that motivates her to go, usually to the physician, in an attempt to clarify her doubts both about the causes of neonatal jaundice in her baby and the phototherapeutic treatment. However, this need for understanding by the mother is not always satisfied by the professional, as Mother 8 said:

[...] When the doctor came to examine my baby, I asked him if she was having any problems. He explained me superficially, saying that he was evaluating the baby to see if she was yellow. I asked if the baby was. He replied, "Ah! I have to look at the table. He's gone [...]. I tried to talk to the doctor in the 
hallway and could not because I was crying a lot. I panicked because that child was my baby. Then he told me that the resident doctor would come and talk to me and explain $[\ldots]$.

After receiving the bad news, feeling shocked, and trying to understand the situation in which her baby is, the mother ends up frustrated with the suspension of the NB's hospital discharge (A4); in the face of maternal deprivation of what is expected (discharge of the NB), after receiving the news that the expected hospital discharge in 48 hours of life would be suspended, beginning then the phototherapeutic treatment for jaundice.

[...] In the beginning, I was happy, thinking that I would have hospital discharge. [...] I was not able to stay here any longer because I was suffering a lot, when the nurse arrived and said that my baby's examination had given a few problems, and then he would have to take light's bath. I got sad. I cried and called my mother [...] (Mother 2).

Thus, the prolongation of hospitalization refersfeeling recluse, separated from her baby, accountable and with not enough support for care (B) by the members of the multi-professional team that work there, an experience that signals the worsening of maternal suffering.

In face of this treatment for jaundice, the nursing team delegates to the mother the function of continuously monitoring the maintenance of the eye protector in her baby, so that it ensures that there is no lesion of the corneas, that is, she is held accountable for the NB's vision integrity (B1), as well as hygiene and food care, as said Mother 11:

[...] I could not sleep. I had to watch the baby, to make sure the glasses were protecting those little eyes, and still had to breastfeed him. Someone in the nursing said I had to nurse him every two hours. So that the yellow of skin was eliminated faster. So I was not even sleeping. It was difficult! [Silence].

Taking on the role of protector, the mother considers herself suffering to see the baby's eyes blindfolded (B2). They report as being painful the interaction with the baby crying, angry because of protective glasses. These go beyond barriers to incidence of light in the baby's eyes, but also to non- verbal mother-child communication, as they related:

[...] I have been suffering a lot in seeing my baby blindfolded, crying, struggling. He must feel like he's in the $\operatorname{dark}[\ldots]$ (Mother 10).

In a constant state of alertness, in the exercise of protective mother of NB in phototherapy, she is impelled to remain depriving herself from sleep and rest (B3). Exhausted, between naps, either at night or during the day, the mother often finds herself frightened by the baby, sleeping or not , without the protective glasses, blaming herself for imagining that the baby's visual acuity may have been affected. Therefore, she despairs and feels impotent, through the exhaustion caused by the exercise of her role in the treatment, added to the stress with the labour. And this accumulated stress interferes with the mother-child relationship, as they said:

[...] I woke up twice during the night. Thank God, he had his eyes closed without his protective glasses. I got desperate, for thinking that he could have opened his eyes without the protection and the light injured his eyes. I got sad about all this [...] (Mother 2).

[...] You stay the whole time in that tension and then you do not sleep. I even try to take a nap, but I cannot. I hear a little baby noise and I run to see if she's trying to take the eyeshade. Sometimes I do not even lie down; I sit on the bed watching her, because I cannot get her out of the crib. So I watch over her sleep all night, so that nothing worse will happen. I have to stay up day and night because I have no one to help me watch over my baby [...] (Mother 1).

As a result, the mother feeling uncomfortable about disturbing sleep in rooming-in care (B4), increases her stress by realizing that her baby's crying is contributing to sleep and rest disturbance of the other mother-NB binomials.

[...] How do you leave a baby crying all the time? You cannot leave! [...] No one sleeps in the bedroom. The baby does not sleep, becomes tired and more agitated. It 
gets worse. Then there is no way to proceed with the treatment, and so I end up staying up all night with her [...]. It brings sadness! (She silences and cries). I hear her cry and sometimes I even cry with her [...] (Mother 1).

Facing these challenging events, the mother ends up feeling reclusive with the prolonged hospitalization (B5), once contradicted and consequently saddened by the permanence in the hospital, in the conditions already put, said Mother 1:

[...] The days are getting longer and longer. I do not live in this city and now this hospital has practically become my home. I've been here for more than 10 days; just taking care of my baby. My psychological is all messed up [...]. You see all the mothers going away with their children, and you end up just being here. I ask myself: will I stay here all my life? It is not easy being away from home $[\ldots]$.

The experience movement indicates that much of the physical and psychological burden of being a mother of NB in phototherapy is due to the fact that the puerperal woman perceives herself in a difficult situation of not counting on support (B6) neither from their family members nor members of the multi professional team to meet any of these physiological needs such as sleep and rest. The mother, most of the time, is weeping, exhausted, in the absence of someone who replaces her until she re-establishes her energies through rest, to continue playing the protective role of the NB. They cry and do not always count on help and guidance from the multi professional team on how to slow down crying and, consequently, the child's suffering, that is, the binomial's, reports Mother 8:

[...] A lot of things start to happen and you ask the nurse for help and she replies that it is normal. The first response saying it is normal you accept, from the second and on you start to find it strange that no one can help you (tremulous voice). Then the time goes by. All the time, you end up asking someone to help you, asking if you can give a pacifier, that is, what you could do to stop the baby from crying, to stay in the crib under the light $[\ldots]$. The Doctor does not say anything! [Cry] $[\ldots]$
Resigning to the protective role of a baby in suffering and at risk (C) is the third sub process of the experience, when the mother renounces the satisfaction of her own needs to the benefit of the NB, entirely dependent on her care, reports Mother 2:

[...] When I realized that my baby really needed the treatment, (silence), I decided to stay here, but I confess that I am sad. I want to leave! I'm here for him. I'm not going home, leaving him here (silence) [...].

Resigned to baby protective role in phototherapy, the mother undertakes movement to the fourth and last sub process of the experience, nominated seeking strategies to deal with the situation (D).

The first attitude of mothers is to try to calm the baby by offering the breast for the baby to breastfeed (D1). The first and main strategy used by the mother to relieve the stress of the $\mathrm{NB}$, even recognizing that the time spent for breastfeeding, would imply the prolongation of treatment time, since during this period the baby remains out of the light spot, interrupting momentarily the phototherapy. However, she strives to exercise her protective role, following the guidelines of the team, seeking to resolve the intercurrences that may hinder or prevent effective breastfeeding, such as: use of silicone nipple, adjust the correct handle to the maternal breast and try to relieve stress, to be psychologically well to breastfeed her baby. Mother 1 related:

[...] The baby who does not sleep gets restless, that is, they get worse. Then there is no way to proceed with the treatment. [...] in this way, I stay up all night with her, because when she cries I pick her up, I offer her breast and if she [...] calms down, I put her back in the crib. Then she sleeps a little longer and after about three hours, she wakes up again and so she wakes up several times during the night $[\ldots]$.

Requesting environmental warm-up (D2) is another strategy employed to promote comfort for the baby, since at night, when there is a drop in temperature and seeing the baby naked and with signs of hypothermia, the mother undertakes movement so that the team promotes the elevation of temperature in the environment, as said Mother 7:

[...] I asked for a heater, because it was kind of cold. My baby [...] was shaking a lot. She 
had her feet and hands frozen. I thought: - I think she must be cold. Then I asked for the heater and she gave it to me. Now I turned it off because she was sweating [...].

Finally, when experiencing the challenges that shape the role of mother of NB in phototherapy, they often find themselves imagining other less aggressive treatments (D3), with concrete possibilities of less psychological impact. As an example: imagining the existence of a medication as a form of treatment; application of light in which there is no danger of corneal injury; another way of treating jaundice, the possibility of only daytime sessions; or even the possibility of a companion who would stood with the binomial throughout the time of phototherapy, as Mother 10 told:

[...] This situation is bad! Horrible! I even wonder that there might be a medication that would help eliminate bilirubin. A medication would be better $[\ldots]$.

Through the realignment of the components that formed the sub processes, a central designated category which covers them may be discovered, constituting then the experience process, called: from suffering to resignation in order to deal with the maternal experience with NB in phototherapy (Figure 1).

\section{Discussion}

Analyzing the movement of the experience of puerperal women entitled,"From suffering to resignation to deal with the maternal experience with NB in phototherapy", the protective role of mother as a symbolic intervening component has been found to prompt her to seek ways of dealing with the challenging experience. In the same way that, the team of rooming-in care emerged in the experience of this mother, using the same symbol, to hold her accountable for constant vigilance in maintaining the integrity of the baby's vision throughout the treatment.

It is emphasized in this experiential movement, aggravating the humanization of care, with symbolic violence perpetrated by the team, once they do not offer sufficient support in the care of the binomial, imprisoning the mother to psychic and physical suffering, with the feeling of impotence in the exercise of a role assigned to her, almost humanly impossible to be fulfilled.

The perpetuation of forms of symbolic violence in health settings is often veiled and therefore more difficult to recognize and, consequently, to be faced or prevented in everyday life. In the experience of mother with newborns in phototherapy, the influence for such concealment can be inferred to the social conception of obligatoriness of the maternal role in the care, through division of roles between the genres, 14 influencing the self of both mother and health team, because according to Symbolic Interactionism, the self is a configured social object in relation to which the individual acts, and this action depends onhowhe/she seeshim/herself, howhe/she defineshim/herself, the judgment he/she makes of him/herself is highly dependent on the social definitions he/she encounters during his/her life. 12

Symbolic violence, for the French sociologist Pierre Bourdieu, is a form of coercion exercised by the body that morally and psychologically affects the other, without physical confrontation. It is a form of constraint that relies on the recognition of a determined imposition, be it economic, social or symbolic. For the author, symbolic violence is the means of exercising symbolic power over the other. 15

It is for these reasons that the mother feels insecure and frightened by the possibility of something wrong occurring with the baby, consequently by her on judgment as well as by the team, family and society's judgment, once aware of her role and emphatically guided by the team about her responsibilities.

A recent study on the process of humanization in the field of power relations analyzed the occurrence of symbolic violence as an aggravating factor in dehumanization in hospitals, with mothers in Neonatal ICU, corroborate results of this research. The study referred to dehumanizing factors far beyond the lack of physical structure of hospitals, such as reports of non-acceptance, hostility and symbolic violence, signaling that the process of humanization passes, above all, through the establishment of less asymmetric relations of power between the hospital staff and the accompanying mothers. 16

This research showed in the continuum of the mother-NB experience in phototherapy, difficulties of establishing therapeutic communication with professionals, at the moment when the mother demanded clarification on the disease and the treatment of the baby, early in the experience, when disappointed by the bad news, as well as subsequently feeling reclusive, separated from the baby, responsible and with insufficient support for 
care.

The review of the literature on the object of research experience of mothers of neonates in phototherapy and health team has been shown to be still challenging the establishment of effective communication. 3,8,17-19 Mothers observe from the professionals: insufficiently provided 3,19 or divergent 8,18 information, with the use of technical terms 18 and evasive responses.Sometimes, demonstrating ignorance of the therapeutics and disinformation about the technological apparatus. On the part of the mothers, the shyness before the health team has been recognized as a barrier to communication. ${ }^{19}$ As a result, many unanswered doubts remain with mothers, 3,19 leading them to insecurity 1,19,20 and distrust, 1,18 even assuming catastrophic outcomes, ${ }^{20}$ such as the separation of the binomial, through its discharge 5 and or risk of death of the NB. 20 Taken by these fears, the mother begins to worry about the clinical evolution of her baby. 19,20

In this study, mothers assume alternative treatments in an attempt to minimize the suffering caused by it, resigned to the perception of the need to continue applying the necessary care to improve health conditions of her newborn.

In addition, these mothers pointed out the need to develop other methods of treatment of Neonatal Jaundice, which could ease the separation of the binomial, such as the use of some medication, but although there are some drugs described in the literature, which are effective in decreasing or inhibiting the increase of serum bilirubin, 21,22 they are usually used together with phototherapy, and the best evidence of treatment for jaundice is still the use of light, with fewer direct side effects to the neonate. 1

It is considered insufficient to invest only in technology with high-emission phototherapy system by optical fiber, in order to minimize mother-child separation and the risk of injury to the corneas of the newborn, but concomitantly to work with the staff issues related to humanization in care.

The mother should be treated as the main subject of the educational relationship established in rooming-in care. The team should be attentive to their doubts, fears, questions and desires to learn, in addition to minimizing the feeling of imprisonment and improving the perception of support, which would make the time experienced meaningful in encouraging the woman to care for her child. ${ }^{23}$

It is considered salutary to schedule, together with the mother, family members or the staff members themselves, a rest period for these mothers, as an assisted right.

In a study in which the exhausted mothers were allowed to take rest breaks, they praised the initiative, since they returned motivated to continue in the rooming-in care. 24

\section{Final Considerations}

The objectives initially proposed were achieved, once the theoretical - methodological approach employed allowed the understanding of the maternal experience with her newborn in phototherapy, entitled "From suffering to resignation in order to deal with the maternal experience with NB in phototherapy".

The symbolic intervening component, the protective role of mother, has propelled her into attempts to cope with the challenging experience by feeling compelled to exercise as a caretaker by the team. In the same way, the rooming-in care team emerged in the experience of this mother, using the same symbol, to hold her accountable for the constant vigilance in maintaining the integrity of the baby's vision.

This research contributed to the unveiling of symbolic violence perpetrated by the health team to the mother with NB in phototherapy, associated with the social conception of the obligation of the maternal role in care, when the latter is deprived of sufficient support, impelling it to psychic and physical suffering, with the feeling of impotence in the exercise of a role attributed to her, almost humanly impossible to be fulfilled in rooming-in care.

Finally, the results of this study indicate the need to review public policies on maternal and child health in the country, even being this study restricted to analyzing the experiences of mothers of NB in conventional phototherapy of a public hospital.For this reason it would be advisable to continue the studies, to verify the experience and perceptions of the team members, as well as to compare this experience with other public institutions, as well as with experiences from private institutions.

In addition, it is recommended to invest in the adoption of technology with high-emission phototherapy system by optical fiber, in order to minimize mother-child separation and risk of injury to the corneas of the NB, while continuing to work with the team on issues related to humanization in assistance to the binomial. 


\section{References}

1. Durán M, García JA, Sánchez A. Efectividad de la fototerapia en la hiperbilirrubinemia neonatal. Enfermería Univ. 2015; 12 (1): 41-5.

2. Emokpae AA, Mabogunje CA, Imam ZO, Olusanya BO. Heliotherapy for neonatal hyperbilirubinemia in Southwest Nigeria: a baseline pre-intervention study. PLoS One. 2016; 11 (3): e0151375.

3. Fernandes JIS, Reis AT, Silva CV, Silva AP. Motherly challenges when facing neonatal phototherapy treatment: a descriptive study. Online Brazilian J Nurs. 2016; 15 (2): 188-95.

4. Souza ABG, Ferreira JS. Hiperbilirrubina Neonatal e Fototerapia. In: Enfermagem neonatal: cuidado integral ao recém-nascido. 2 ed São Paulo: Atheneu; 2014. p. 117-28.

5. Cardoso ACSC, Cardoso MVLML. O recém-nascido sob fototerapia: A percepção da mãe. Rev. Latino-Am Enferm. 2004; 12 (4): 606-13.

6. Machado SPC, Samico IC, Braga TDA. Conhecimento, atitude e prática sobre fototerapia entre profissionais de enfermagem de hospitais de ensino. Rev Bras Enferm. 2012; 65 (1): 34-41.

7. Olusanya BO, Slusher TM. Infants at risk of significant hyperbilirubinemia in poorly-resourced countries: evidence from a scoping review. World J Pediatr. 2015; 11 (4): 2939.

8. Brethauer M, Carey L. Maternal Experience with Neonatal Jaundice. MCN, Am J Matern Nurs. 2010; 35 (1): 8-14.

9. Foreland AM, Rosenberg L, Johannessen B. Nurses' experiences using conventional overhead phototherapy versus fibreoptic blankets for the treatment of neonatal hyperbilirubinemia. J Neonatal Nurs. 2016; 22 (3): 108-14.

10. Tartaglia KM, Campbell J, Shaniuk P, McClead RE. A quality project to improve compliance with AAP guidelines for inpatient management of neonatal hyperbilirubinemia. Hosp Pediatr. 2013;3 (3): 251-7.

11. Strauss AL, Corbin JM. Pesquisa qualitativa: técnicas e procedimentos para o desenvolvimento da pesquisa fundamentada. 2 Porto Alegre: Artmed; 2008. 288 p.

12. Charon JM. Symbolic interactionism: an introduction, an interpretation, an integration. 10 ed. Englewood Cliffs(NJ): Prentice Hall; 1989.

13. Brasil. Portaria $n^{\circ} 1.016$, de 26-08-1993. Aprovar as Normas Básicas para a implantação do sistema "Alojamento Conjunto". Diário Oficial da União. Disponível em: http://www.saude.mg.gov.br/images/documentos/Portaria_GM_MS_1016.pdf.
14. Moura SMSR, Araújo MF. Produção de sentidos sobre a maternidade: uma experiência no Programa Mãe Canguru. Psicol Estud. 2005; 10 (1): 37-46.

15. Miranda L. Pierre Bourdieu and the field of communication: by a theory of praxiological communication. Porto Alegre: EDIPUCRS; 2005.

16. Vieira LR, Mafra LAS M. Humanização hospitalar e violência simbólica: a percepção das mães em UTIs Neonatais [Hospital humanization and symbolic violence: the perception of mothers in neonatal ICUs]. Tempus, Actas Saúde Colet. 2016: 10 (3): 99-114.

17. Souza JJ, Felipe AOB, Terra FS. Phototherapy: the feelings of mothers of newborns undergoing this therapy. Semin Ciênc Biol Saúde. 2013; 33 (2): 231-40.

18. Campos ACS, Cardoso MVLML, Pagliuca LMF, Rossi LA. Comunicação: instrumento básico para cuidar da mãe do neonato sob fototerapia. Rev Rene. 2008; 9 (4): 24-32.

19. Campos ACS, Cardoso MVLML. Enfermagem e o cuidado humanístico: proposta de intervenção para a mãe do neonato sob fototerapia. Ciênc Enferm. 2006; 12 (1): 7381.

20. Campos ACS, Leitão GCM. Crenças e sentimentos vivenciados pelas mães de recém-nascidos sob fototerapia. Rev Gaúcha Enferm. 2005; 26 (1): 50-6.

21. Rafieian-kopaei M. Cotoneaster: A Safe and Easy Way to Reduce Neonatal Jaundice. J Clin Diagnostic Res. 2016; 10 (4): 10-2.

22. Gholitabar M, McGuire H, Rennie J, Manning D, Lai R. Clofibrate in combination with phototherapy for unconjugated neonatal hyperbilirubinaemia. Cochrane Database Syst Rev. 2012. Issue 12 Art. No: CD009017.

23. Costa NS, Parreira BDM, Fonseca-Machado MO, Mattos JGS, Elias TC, Silva SR. Cuidados com recém-nascido realizados por puérperas em um alojamento conjunto $=$ Newborn care by puerperae in rooming-in. Ciênc, Cuid Saúde. 2013; 12 (4): 633-9.

24. Nyqvist K, Anderson G, Bergman N, Cattaneo A, Charpak N, Davanzo R, Ewald U, Ludington-Hoe S, Mendoza S, Pallás-Allonso C, Peláez JG, Sizun J, Widström AM. State of the art and recommendations Kangaroo mother care: application in a high-tech environment. Acta Paediatr. 2010; 99 (6): 812-9.

Received on April 24, 2017

Final version presented on November 13, 2017

Approved on December 7, 2017 